First Peoples Child \& Family Review

A Journal on Innovation and Best Practices in Aboriginal Child Welfare Administration,

\title{
Mental Health Promotion as a Prevention and Healing Tool for Issues of Youth Suicide in Canadian Aboriginal Communities
}

\section{Rachel L. Wortzman}

Volume 4, Number 1, 2009

URI: https://id.erudit.org/iderudit/1069346ar

DOI: https://doi.org/10.7202/1069346ar

See table of contents

Publisher(s)

First Nations Child and Family Caring Society of Canada

ISSN

1708-489X (print)

2293-6610 (digital)

Explore this journal

Cite this article

Wortzman, R. (2009). Mental Health Promotion as a Prevention and Healing Tool for Issues of Youth Suicide in Canadian Aboriginal Communities. First Peoples Child \& Family Review, 4(1), 20-27. https://doi.org/10.7202/1069346ar
Article abstract

This article discusses the appropriateness of using mental health promotion as a prevention and healing tool for Canadian Aboriginal youth dealing with issues of suicide. Strengths of mental health promotion in the context of this population include its emphasis on community-wide approaches, consideration of root causes of mental health issues, recognition of culture as a protective factor, and integration of diverse forms of knowledge. Limitations include an inadequate role for spirituality, lack of culturally-sensitive program evaluation, and emphasis on Western patterns of time, space, and communication. In response to this analysis, recommendations are proposed that could guide the development of future mental health promotion programs.
This document is protected by copyright law. Use of the services of Erudit (including reproduction) is subject to its terms and conditions, which can be viewed online.

https://apropos.erudit.org/en/users/policy-on-use/ 


\section{Mental Health Promotion as a Prevention and Healing Tool for Issues of Youth Suicide in Canadian Aboriginal Communities}

\author{
Rachel L. Wortzman ${ }^{a}$ \\ ${ }^{a}$ BHSc, MHSc Health Promotion (Candidate), Dalla Lana School \\ of Public Health, University of Toronto, Canada
}

\section{Introduction}

In Western society, the concept of mental health is often based on the assumption that reducing the number of cases of mental illness will result in a mentally healthier population (Keyes, 2007). Embedded within this assumption is an extremely important, but fundamentally flawed, hypothesis: the absence of mental illness is the presence of mental health. This hypothesis has been questioned for several reasons, not least of which is that the distinctions between mental disorders, as outlined in the Diagnostic and Statistical Manual of Mental Disorders (DSM 1V), can be ambiguous and arbitrary. Some scholars even question whether mental illness can exist as an objective physiological malfunction (MacDonald, 1999). If the criteria used to define mental illness are unclear, then it becomes inappropriate to classify mental health as the absence of mental illness. Moreover, only a small proportion of individuals otherwise free of a common mental illness actually experience high levels of mental wellbeing (Keyes, 2007). Focusing solely on mental illness will therefore have no positive bearing on promoting mental health.

As marginalized segments of Canada's population feel increasingly disenfranchised from this traditional view of mental health, new conceptions and approaches are slowly gaining respect. One such approach is the theory of mental health promotion. This theory posits that people have an intrinsic capacity to cope with and enjoy life, even if it is not evident at a given moment. In the context of supportive

Questions or correspondence concerning this article may be addressed to:

rachel.wortzman@gmail.com

\begin{abstract}
This article discusses the appropriateness of using mental health promotion as a prevention and healing tool for Canadian Aboriginal youth dealing with issues of suicide. Strengths of mental health promotion in the context of this population include its emphasis on community-wide approaches, consideration of root causes of mental health issues, recognition of culture as a protective factor, and integration of diverse forms of knowledge. Limitations include an inadequate role for spirituality, lack of culturally-sensitive program evaluation, and emphasis on Western patterns of time, space, and communication. In response to this analysis, recommendations are proposed that could guide the development of future mental health promotion programs.
\end{abstract}

environments that provide access to health-determining resources, people are best able to decide what they want out of life and what is required to bring about those ends (Joubert \& Raeburn, 1998).

The objective of this article is to examine the appropriateness of mental health promotion as a prevention and healing tool for Canadian Aboriginal youth who have experienced suicidal ideation or have attempted suicide in the past. By placing traditional healers and community members at the centre of the healing process, with Western practitioners as secondary helpers to these traditional healers, mental health promotion has the potential for offering a culturally-sensitive approach to healing that can be integrated into a diverse range of Canadian Aboriginal communities. This article will discuss the theory of mental health promotion and its intersection with the issue of youth suicide in Aboriginal communities. This will be followed by a discussion of the strengths and limitations of mental health promotion in the context of this population. It will then conclude with recommendations and guidelines that merit consideration when developing mental health promotion programs targeting youth suicide in Canadian Aboriginal communities. 


\section{Theory of Mental Health Promotion}

Although many definitions of mental health promotion exist in the literature, arbitrary definitions tend to leave a number of assumptions and values unquestioned, focus too heavily on individual-level factors compared to the social context, and do not adequately allow for the complex and subjective nature of mental health promotion (MacDonald, 1999). Instead, a variety of literature sources should be combined to provide a suitable and comprehensive understanding of a theory.

Mental health promotion can be identified at the micro, meso, and macro levels of society. At the micro level, health promotion efforts are aimed at improving an individual's resiliency, which is a quality that allows people to function well despite negative odds (Pape \& Galipealt, 2002). Resiliency is supported by protective factors, which buffer a person in the face of adversity; and hindered by risk factors, which increase a person's susceptibility to poor mental health. Protective factors include social skills, support from peers and family, positive school climate, and sense of belonging, while risk factors can be described as insecure attachment, family violence, negative life events, poverty, and community instability (Centre for Addiction and Mental Health, 2009).

To achieve resiliency, protective factors must be facilitated through supportive environments (Pollett, 2007). The support of family, peer groups, workplaces, and communities comprise the meso level of mental health promotion. This level assumes that if people have access to relevant, usable, and supportive resources that are tailored to their needs, culture, and stage of life, then they can collectively engage in a process of empowerment and recovery (Joubert \& Raeburn, 1998). Implicit in the meso level is the idea that mental health promotion should direct its efforts toward the community as a whole, as communities establish norms that direct behaviour and provide social support that help people cope with challenging situations (Kirmayer, Boothroyd, Laliberte, \& Simpson, 1999).

The macro level focuses on the wider systems that govern and shape many aspects of our lives, including the social determinants of health and government institutions. This level is concerned with the enactment of social justice into policy and law (MacDonald, 1999). It necessitates addressing the root causes of poor mental health, which include income and social status, available mental health services, social support networks, education, physical environments, biology, childhood development, employment opportunities, and culture (Pape \& Galipealt, 2002).

A model of mental health promotion developed by MacDonald and O'Hara (1996) is helpful in explaining the theory in the context of this article, as it accounts for elements at all three levels of society (micro, meso, and macro). According to this model, mental health can be promoted by helping all people, regardless of their mental health status, find ways of participating in society, developing their personal self-management skills, cultivating their abilities to acknowledge and work with their emotions, enhancing or repairing self-esteem, and improving the quality of the environments in which they reside. There is also a need to diminish alienation and exclusion; reduce stress that people experience; and challenge all acts of emotional abuse, negligence, and environmental deprivation. This model appears to suggest that each factor can be enhanced or demoted at the micro, meso, and macro levels. It fails to differentiate, however, between the strategies that would be employed at each particular level to bring about positive ends. Despite this limitation, the model acknowledges both promoting and demoting elements of mental health, does not attempt to over-simplify a complex issue, and remains culturally sensitive in that what counts as exploitation, social support, and environmental quality are left open to cultural and social interpretation (MacDonald, 1999). This cultural sensitivity is extremely important in the context of Canadian Aboriginal society.

\section{Target Population}

The term "Aboriginal" is used throughout this article for its inclusive properties, as it can describe Native, Métis, Indian, or First Nations people in Canada (McCormick, 2005). Aboriginal youth living in Canada are faced with conflicting messages. On one hand, they are influenced by a traditional worldview that shapes their belief system, assumptions, and modes of problem solving. Although this worldview varies according to tribe, level of acculturation, and other personal characteristics, there are some commonalities such as the relationship between people and the land, wholeness, spirituality, and a sense of collectiveness that can be used to identify the Canadian Aboriginal perspective (France, 1997). Consistent with this worldview is the idea that all things are interrelated. According to McCormick (1996), "interconnectedness can be viewed as the individual's connection to the world outside the self. Practically, this means to become connected or reconnected to friends, family, community, and culture" (p. 168). Since all things are interrelated, wellbeing is based on ensuring that one is in harmony with one's surroundings. When a person's physical, mental, emotional, or spiritual wellbeing is out of balance, illness is believed to ensue (Smye \& Mussell, 2001).

This worldview is in stark contrast to the images of global youth culture that Aboriginal young people encounter in their daily lives or through mass media. These images reveal youth enjoying freedom, material wealth, and excess consumption (Kirmayer et al., 1999). Such images are not 
only inconsistent with the Aboriginal worldview, but they also conflict with the daily realities that some Aboriginal youth face. The effects of being physically, emotionally, culturally, and spiritually mistreated by European settlers and the Canadian government have profoundly affected the psyche of Aboriginal people to this day (France, McCormick, \& Rodriguez, 2004). In many Native communities, this cultural oppression has resulted in economic uncertainty, limited job opportunities, and few positive expectations of youth for the future (Kirmayer et al., 1999).

These conflicting messages have led many Aboriginal youth to experience an identity crisis. Although this crisis of identity is amplified in Aboriginal communities - at rates three to six times higher than the general population - it is a fact of life shared by many young people regardless of their culture or ethnic background (Health Canada, 2002; Kirmayer, Simpson, \& Cargo, 2003). According to Erik Erikson's Psychological Stages of Development, youth between the ages of thirteen and nineteen are exploring their independence and developing a sense of self. Some youth experience an identity crisis and use peers to reflect their identity back to them. If they resolve the crisis, youth will emerge from this stage with a strong sense of self and feelings of independence and control. If they fail to resolve the crisis, youth will remain insecure and confused about their role in society and their future (Health Canada, 2002). This confusion, coupled with a potential loss of valued relationships, interpersonal conflict, and perceived pressure for high scholastic achievement can be overwhelming. Many young people feel that the world does not respond to what they have to offer or that they lack the competencies to fulfill the world's expectations and requirements (Joubert \& Raeburn, 1998). If one believes himself or herself to be a failure, then feelings of worthlessness and hopelessness are likely to result. Youth within Aboriginal communities may find it especially challenging to emerge from Erikson's stage of development with a strong sense of self, as they are often torn between two worlds; the world of their traditional, indigenous values and the modern, pervasive world of youth culture depicted in the media (Health Canada, 2002). Indeed, when the Canadian Institute of Child Health (2000) compared First Nations and non-First Nations suicide rates from 1989-2003 for 15-24 year olds, it found that the rate of suicide among First Nations young people was significantly higher than the national average. Among First Nations men between the ages of 15-24, the suicide rate was 126 per 100,000 , compared to 24 per 100,000 for Canadian men of the same age group. Young women from First Nations registered a rate of 35 per 100,000 versus only 5 per 100,000 for Canadian women. Mental health promotion, with its emphasis on inner strength, supportive environments, and latent resiliency, can be seen as an appropriate prevention and healing tool for addressing the internal conflict that underlies much of youth suicide in Aboriginal communities.

\section{Strengths of Mental Health Promotion}

One of the most profound strengths of mental health promotion is its emphasis on the entire community. In the context of this theory, community refers to people united through social bonds, common interest, or locality (Joubert \& Raeburn, 1998). Traditionally, Aboriginal people have practised informal helping by reaching out to their families, friends, and neighbours in times of need (France et al., 2004). This implies a long tradition of treating everyone in the community with respect, support, and dignity, and indicates that taking a community-wide approach to the prevention and treatment of youth suicide would be perceived as customary for many Aboriginal people. France (1997) further explains that the goal of healing in Aboriginal communities is not to strengthen a person's ego, but rather to encourage that person to transcend the ego by considering oneself as embedded in and expressive of the community. This can be accomplished through traditional ceremonies, such as the Vision Quest, which is a method of opening oneself to the spirit world by isolating oneself in the wilderness; and the Sweat Lodge, which is a method of purification that demonstrates respect to Mother Earth and all creation (France, 1997). These traditional ceremonies reinforce the importance of keeping family and community networks strong and can be integrated into a communitywide program aimed at healing Aboriginal youth. Another advantage of a community-wide approach is its capacity to avoid stigmatizing certain youth as suicidal within the community. Stigma can impact a youth's ability to access employment, education, and community activities (Pape \& Galipealt, 2002). Programs that focus on the entire community can help marginalized individuals, such as youth struggling with suicidal ideation or past suicide attempts, to become better integrated into the community, and may even play a role in gradually shifting commonly held negative attitudes about youth suicide among members of the community.

The Community-Based Suicide Prevention Program in Alaska provides an example of the benefits that can be achieved when using a community-wide approach for Aboriginal youth suicide prevention. Developed and implemented by Alaskan Native communities, this program is unique in that local indigenous planning groups were required to form within each community to determine the needs of the community and oversee program activities before the program could be executed. Many aspects of this program focus on traditional activities that promote cultural values, such as elder and youth exchanges, where elders share traditional knowledge and wisdom with younger generations (Kirmayer et al., 1999). A program 
evaluation conducted between 1989 and 1993 revealed that this project began in communities with higher suicide rates than the overall rate for Alaskan Natives, but at the end of three years, rates in project communities declined faster than state-wide Alaskan Native rates (Kirmayer et al., 1999). This evidence supports the notion that the strength of social bonds in many Aboriginal communities and the willingness to act for the benefit of the group provides a social support network in which community-based mental health promotion programs can flourish.

A second strength of mental health promotion is its explicit focus on the root causes of mental health issues. According to MacDonald (1999), many of life's ups and downs are not inevitable, but rather socially constructed. These instabilities are the result of social injustices, inequities, and health-demoting policies. The World Health Organization (2007) further explains that substance abuse, violence, and feelings of depression are more prevalent and difficult to cope with in conditions of high unemployment, low-income, limited education, stressful working conditions, gender discrimination, social exclusion, and human rights violations. This indicates that to successfully prevent youth suicide, one must focus on the underlying factors that contribute to feelings of depression in the first place.

This approach may be extremely relevant for Canadian Aboriginal youth, who continue to experience intergenerational trauma, poverty, unemployment, and inadequate housing in their daily lives (Smye \& Mussell, 2001). Much of these unhealthy living conditions can be traced back to the impact of European colonialism. Early missionary activities focused on forced religious conversion by suppressing existing Aboriginal practices that were integral to their subsistence (Kirmayer et al., 2003). This placed many Aboriginal communities in a state of poverty and highly reliant on charitable and emergency food relief, which is not compatible with human dignity or good health. The later apprehension of Aboriginal children from the family, community, and cultural context via the residential school system and forced adoption into non-Aboriginal families has resulted in problems of identity and selfesteem for individuals growing up in unfamiliar and hostile conditions (Kirmayer et al., 2003). Experiences of physical and sexual abuse, emotional neglect, internalized racism, language loss, and suicide have been passed down through generations, and still affect Canadian Aboriginal youth to this day (Kirmayer et al., 2003). Transgenerational effects include the transmission of explicit models of parenting based on experiences in punitive institutional settings; patterns of emotional responding that reflect a lack of warmth and intimacy in childhood; and a loss of knowledge, language, and tradition that has led to the systematic devaluing of Aboriginal identity (Kirmayer et al., 2003; Shepard, O'Neill, \& Guenette, 2006; Wilson, 2004).
Given this profound history of cultural oppression, programs endeavouring to heal Aboriginal youth who have experienced suicide ideation or attempted suicide in the past must address the root causes of their psychological pain. For example, programs could improve access to safe, affordable, and secure housing in ways congruent with the community and family orientation of many Aboriginal people. Research suggests that housing is one of the most salient considerations in mental health planning, as those unable to access appropriate housing have significantly reduced quality of life (Smye \& Mussell, 2000). Regrettably, 25 percent of Canadian Aboriginal people living in metropolitan areas in 2001 experienced inadequate, unsuitable, and unaffordable housing, compared to only 13.5 percent of non-Aboriginal households (Canada Mortgage Housing Corporation, 2004). The Urban Native Housing Program (UNHP), delivered by the Canada Mortgage and Housing Corporation, grew out of a recognized need for culturally appropriate social housing for Aboriginal people coming from rural or reserve communities to urban areas. All units of housing developed under the UNHP were administered by local Aboriginal housing organizations and overseen by boards of directors and staff comprised mainly of Aboriginal people. Counsellors were also available to help tenants adjust to their new home environment. An evaluation of urban social housing programs in Canada found that a significantly higher proportion of Aboriginal tenants in UNHP had improved access to social services, had made more friends and felt more secure, settled, and independent compared to Aboriginal tenants in mainstream social housing (Walker, 2009). Despite this important piece of evidence, there has been virtually no research conducted on the emotional and psychological benefits of providing housing to Aboriginal peoples using culturally meaningful approaches (Mussell, Cardiff, \& White, 2004). This indicates that very little has been done to address the relationship between housing and wellbeing, and exposes a worthwhile target for future mental health promotion planning.

A key goal of mental health promotion is to enhance protective factors as a way of moderating the impact of negative life events on social and emotional wellbeing (Centre forAddictionandMentalHealth,2009). Recognizing and valuing culture as an essential protective factor in this process is a third strength of mental health promotion in the context of Aboriginal society. McCormick (2000) acknowledges that to be disconnected from cultural values is to be disconnected from potential sources of meaning. This disconnect from traditional values was a deliberate strategy used by churches and the government of Canada in an attempt to assimilate Aboriginal people into Western culture. Prior to colonization, adolescence was not viewed as a distinct period in the life cycle between childhood and adulthood. Rather, young people in Aboriginal communities functioned as adults with responsibilities for subsistence 
activities and raising families (Kirmayer et al., 2003). With colonialism, the socialization of youth changed their role from a responsible member of the community to a passive recipient. Youth were largely excluded from community decision-making and left without clearly defined direction (Kirmayer et al., 2003).

Evidence suggests that disconnect from traditional culture is associated with high rates of suicide. A study conducted by Chandler and Lalonde (1998) rated Aboriginal communities in British Columbia on seven measures of cultural continuity. These included: 1) self-government; 2) involvement in land claims; 3) band control of education; 4) health services; 5) cultural facilities; 6) police; and 7) fire services. Communities with all seven factors had extremely low suicide rates, while those with none of the factors had extremely high rates. This indicates that not all Aboriginal communities are affected by suicide to the same extent. Communities that have taken active steps to preserve and rehabilitate their own culture are those in which youth suicide rates are lowest.

Mental health promotion, with its emphasis on participatory decision making and personal and collective empowerment, may represent an opportunity to reintegrate traditional healing practices into the lives of Aboriginal youth who have experienced suicidal ideation or have attempted suicide in the past. Knowledge of living on the land, community connectedness, and historical consciousness all provide sources of resiliency, where youth are better able to cope with significant adversity in positive and healthy ways (Kirmayer et al., 2003). An example of cultural and spiritual revival as a tool for healing can be found in Alkali Lake, British Columbia. This Aboriginal community used traditional healers to help its members revive time-honoured dances, ceremonies, and spiritual practices, such as pow-wows, sweetgrass ceremonies, sweat lodges, and drumming circles. The guiding philosophy of this treatment program was: "culture is treatment, and all healing is spiritual". Within ten years of initiating this cultural revival, alcohol consumption within the community decreased from $95 \%$ to $5 \%$ (McCormick, 2000). In this case, recuperating lost traditions reconnected Aboriginal people to their historical roots and mobilized practices to promote community solidarity. These are critical goals of mental health promotion, as cohesive, vibrant communities can provide the social support necessary to overcome challenging life events and promote positive mental health.

The emphasis that mental health promotion places on understanding health from multiple perspectives and adopting an intersectoral approach can be seen as a final strength in its relation to Aboriginal youth. Health promotion, which is the larger discipline of which mental health promotion is a part, defines health as a state of complete physical, mental, and social wellbeing, and not merely the absence of disease or infirmity (World Health Organization, 1986). This definition implies that the prerequisites and prospects for health cannot be ensured by the medical sector alone. Indeed, mental health promotion programs are based on many sources of knowledge other than clinical, such as social science, experiential, customary, and traditional (Pape \& Galipealt, 2002). Using these different approaches in an integrated and balanced way is consistent with aspects of the Canadian Aboriginal worldview. This view asserts that one part of a person cannot be central, but must instead learn to work in harmony with all other parts. This sense of balance is seen as necessary because the world itself is in balance among transcendental forces, human beings, and the natural environment (France, 1997).

By respecting diverse sources of knowledge and incorporating them into practice in a balanced manner, mental health promotion can demonstrate to Aboriginal youth that one aspect of a person's life should not supersede all other parts. Interpersonal relationships, difficulties in school, conflict with authority figures, and low-self esteem can feel overwhelming during adolescence, and consequently eclipse other enjoyable parts of life. Mental health promotion, in accordance with the Aboriginal worldview, would encourage youth to view their lives on more holistic terms and find balance in thoughts, feelings, and actions (France et al., 2004).

An example of a mental health promotion program that employs an integrated approach to healing is the Miyupimaatisiiuwin Wellness Curriculum offered by Cree Public Health in Montreal, Quebec. This school-based curriculum is dedicated to taking a holistic and comprehensive approach by covering a wide range of wellness issues. The program focuses on "wellness" because this term includes physical, mental, and spiritual health. All programming within the Miyupimaatisiiuwin curriculum is offered in an integrated manner. The curriculum is designed for students in kindergarten through to grade eight, but also reaches parents through a planned parental informed consent component built into each lesson. Relevant issues are extended and developed through the grades in a spiral manner with issues reappearing at each level in a more complex form (Kirmayer et al., 1999). By ensuring that all aspects of the program are interconnected, the Miyupimaatisiiuwin curriculum is congruent with the Aboriginal belief that wellbeing ensues when one is in harmony with his or her surroundings (France et al., 2004).

As the aforementioned discussion suggests, mental health promotion is a valuable theory to draw upon when developing prevention or healing programs for youth suicide in Aboriginal communities. There are, however, some features of this theory that limit its applicability in the Canadian Aboriginal context. 


\section{Limitations of Mental Health Promotion}

Mental health promotion can be adopted differently depending on its context, but very few discussions of mental health promotion recognize spirituality as an important dimension. For instance, the conceptual model of mental health promotion discussed in an earlier section of this article, is one of the most comprehensive models available, and yet still does not account for spirituality. MacDonald (1999), one of the authors of this model, acknowledges his apparent oversight by saying, "There has been some recent criticism that the map has no spiritual dimension, except for what might be included in the emotional processing element...My own bearing witness to this issue in our culture comes up with contradictory observations. And so, overall, we think that in our culture and at this time there are ten elements involved in mental health [not including spirituality]" (p. 41). The inability to recognize spirituality as a crucial dimension of wellbeing suggests that this model was designed for use predominantly in Western cultures. Indeed, many non-Native counselling approaches rarely deal with the spiritual aspects of people (McCormick, 1996). In contrast, spirituality plays a fundamental role in Canadian Aboriginal society and its use as a tool for healing would be unequivocal in most contexts. Spirituality can be described as getting beyond the self in order to connect with the rest of creation (McCormick, 2000). A study examining the development of a culturally sensitive framework for counselling with first Nations people determined that spirituality was one of the most important themes in the healing process for First Nations clients (McCormick, 1996). Ultimately, if mental health promotion is to be used effectively in the context of youth suicide in Canadian Aboriginal communities, then it must re-examine spirituality and transcendental ways of understanding the world.

A second limitation of mental health promotion is the lack of evaluation that has accompanied many programs and interventions. The fact that a program continues to exist is often taken as an indicator of its success. While this may be true, evaluation is an important component of program development, as it helps ensure optimal use of time and resources, determines if the program is meeting the needs of participants, and maintains accountability to stakeholder groups (The Health Communications Unit, 2007). There is an urgent need for research to evaluate suicide prevention and mental health promotion programs in terms of their effectiveness, feasibility, and wider social impact (Kirmayer et al., 1999). Health promotion, however, proceeds by small, incremental steps, with beneficial outcomes often considerably delayed (Health Canada, 1997). This indicates that health promotion can only be evaluated over an extremely long time frame, making it an unattractive feat for funders and practitioners alike.
Problems with evaluation are amplified in Canadian Aboriginal communities, as many Aboriginal people are distrustful of the research process due to unethical experiences throughout Canada's history. Concerns include inadequate protection of individual and group identity, exposure to potential harms posed by research, involuntary participation, and stigmatization of individuals and communities as a result of negative research findings (Castellano, 2004). Formental health promotion to overcome these challenges, it must approach evaluation in Aboriginal communities with extreme care and caution. The Royal Commission on Aboriginal Peoples (2006) outlines a set of ethical guidelines for research in Aboriginal communities. These include establishing collaborative procedures to enable community representatives to participate in the planning, execution, and evaluation of research findings; ensuring that a representative cross-section of community experiences are included; distributing results of community research as widely as possible within participating communities; using non-technical and Aboriginal languages where appropriate; obtaining informed consent at all times; and incorporating perspectives on the subject of inquiry that are distinctly Aboriginal.

Even if mental health promotion was to acknowledge the importance of spirituality and adopt more culturallysensitive evaluation methods, a fundamental limitation of this theory still remains. At its core, mental health promotion is predominantly a Western conceptualization based on Eurocentric notions of time, space, and communication. These conceptions bear a cultural orientation, set of values, theory of knowledge, highly specialized forms of language, and structures of power that are distinctly different from Aboriginal conceptions.

Western society has adopted a linear concept of time, which accepts that time is chronological and moving in one direction. Space is seen as consisting of parallel or elliptical lines, which has led to the emergence of disciplines such as geography, geometry, and physics (Janca \& Bullen, 2003; Smith, 1999). In terms of communication, silence is negatively valued and has come to be interpreted as disrespectful and as a lack of understanding (Covarrubias, 2007). These distinctions are generally part of a takenfor-granted view of the world and are frequently used in both everyday and academic discourses. In contrast, the traditional Canadian Aboriginal worldview asserts that there are positions within time and space in which people and events are located, but these cannot necessarily be described as distinct categories of thought (Smith, 1999). In Aboriginal communities, lengthy periods of silence are customary in conversation and are used to listen to what is being communicated non-verbally (Covarrubias, 2007). This indigenous worldview has been undervalued and marginalized in Western society. For example, sacred spaces have been appropriated from Aboriginal peoples 
and then given back as controlled pockets of land known as reservations. Ideas about progress and time have led to portrayals of Aboriginal people as being lazy, devoid of strong work ethic, and possessing low attention spans. Traditional languages have been oppressed and replaced by European languages through the forced residential school system (Smith, 1999).

These conflicting notions of time, space and communication patterns not only pose challenges to the development and implementation of mental health promotion programs in Aboriginal communities, but they also contribute to the further colonization of Aboriginal peoples by applying a model that has a partial fit with indigenous worldviews. Space is needed where Aboriginal young people can address their own needs and priorities from a perspective that fully respects and incorporates traditional knowledge and epistemologies.

\section{Summary and Conclusion}

This article exposes some of the strengths and limitations involved in applying a predominantly Western theory of mental health to a population of Canadian Aboriginal youth who have experienced suicidal ideation or have attempted suicide in the past. On one hand, mental health promotion is relatively progressive and accommodating in its approach to mental health. By emphasizing community-wide approaches, addressing the root causes of mental health issues, acknowledging culture as an important protective factor, and balancing diverse forms of knowledge, this theory is highly consistent with many aspects of the Canadian Aboriginal worldview. On the other hand, mental health promotion does not adequately address spirituality, lacks culturally-sensitive modes of program evaluation, and focuses on Western patterns of time, space, and communication, which may inadvertently impose a colonizing framework. These limitations should not imply that mental health promotion would be an ineffective prevention or healing tool for Canadian Aboriginal youth who have experienced suicidal ideation or have attempted suicide in the past. Rather, they suggest the need for reflection and careful consideration when developing mental health promotion programs in any ethnic and culturally diverse community. Based on lessons learned from this analysis, mental health promotion programs targeting youth suicide should be addressed from biological, psychological, sociocultural, and spiritual perspectives; locally-initiated, owned, and accountable; responsible for the entire community; monitored and evaluated using appropriate methods and on an ongoing basis; rooted in Aboriginal culture; and facilitated in a manner that encourages participants to have a voice in program development, implementation, and evaluation. In addition to these considerations, mental health promotion teaches us that Canadian Aboriginal mental health issues cannot be effectively addressed unless they are part of a wider discourse that includes cultural identity, the natural environment, indigenous leadership, and socio-economic realities (Durie, 2004). After centuries of being viewed by the majority culture as disempowered, perhaps it is time to embrace a theory of mental health that focuses on the tremendous strengths of Aboriginal people.

\section{References}

Canada Mortgage Housing Corporation. (2004). 2001 Census Housing Series Issue 6: Revised Aboriginal Households. Ottawa, Ontario: CMHC.

Canadian Institute of Child Development. (2000). The Health of Canada's Children: A CICH Profile (3rd Ed.). Ottawa, Ontario: CICD.

Castellano, M.B. (2004). Ethics of Aboriginal research. Journal of Aboriginal Health, 1(1), 98-114.

Centre for Addiction and Mental Health. (2009, January 16). Best practices guidelines for mental health promotion programs: Children \& Youth. Retrieved February 29, 2009, from http:// www.camh.net/About CAMH/Health_Promotion/Community_Health_Promotion/Best_Practice_MHYouth/index. $\underline{\mathrm{html}}$.

Chandler, M.J. \& Lalonde, C. (1998). Cultural continuity as a hedge against suicide in Canada's First Nations. Transcultural Psychiatry, 35(2), 191-219.

Covarrubias, P. (2007). (Un)biased in Western theory: generative silence in American Indian communication. Communication Monographs, 74(2), 265-271.

Durie, M. (2004, September). Indigeneity, and the Promotion of Positive Mental Health. Paper presented at the Third World Conference for the Promotion of Mental Health and Prevention of Mental and Behavioural Disorders.

France, H. (1997). First Nations: helping and learning in the Aboriginal community. Guidance and Counselling, 12(2), 3-8.

France, H., McCormick, R., \& Rodriguez, C. (2004). The red road: culture, spirituality, and the sacred hoop. In C. Rodriguez, G. Hett \& H. France (Eds.), Diversity, Culture and Counselling: A Canadian Perspective (pp. 265-281). Calgary, Alberta: Detselig Enterprises Ltd.

Health Canada. (1997). Health promotion in Canada - a case study. Health Promotion International, 13(1), 7-26.

Health Canada. (2002, October). A Report on Mental Illnesses in Canada. Ottawa, Ontario: Health Canada Editorial Board Mental Illnesses in Canada.

Janca, A. \& Bullen, C. (2003). The Aboriginal concept of time and its mental health implications. Australasian Psychiatry, 11(S1), S40-S44.

Joubert, N. \& Raeburn, J. (1998). Mental health promotion: people, power and passion. International Journal of Mental Health Promotion, 1, 15-22. 


\section{First Peoples Child \& Family Review, Volume 4, Number 1, 2008}

Keyes, C.L.M. (2007). Promoting and protecting mental health as flourishing. American Psychologist, 62(2), 95-108.

Kirmayer, L.J., Boothroyd, L.J., Laliberte, A., \& Simpson, B.L. (1999). Suicide Prevention and Mental Health Promotion in First Nations and Inuit Communities. Montreal, Quebec: Culture and Mental Health Research Unit, Jewish General Hospital.

Kirmayer, L.J., Simpson, C., \& Cargo, M. (2003). Healing traditions: culture, community and mental health promotion with Canadian Aboriginal peoples. Australasian Psychiatry, 11, S15-S23.

MacDonald, G. (1999). Problems, possibilities, people, power and passion: what mental health promotion is and what it is not: a response to the inaugural issue. International Journal of Mental Health Promotion, 1(2), 37-43.

MacDonald, G. \& O'Hara, K. (1996). Ten Elements of Mental Health, its Promotion and Demotion: Implications for Practice. Birmingham, United Kingdom: Society of Health Education \& Health Promotion Specialists.

McCormick, R. (1996). Culturally appropriate means and ends of counselling as described by the First Nations people of British Columbia. International Journal for the Advancement of Counselling, 18, 163-172.

McCormick, R. (2000). Aboriginal traditions in the treatment of substance abuse. Canadian Journal of Counselling, 34(1), 25-32.

McCormick, R. (2005). The healing path: what can counselors learn from Aboriginal people about how to heal? In R. Moodley \& W. West (Eds.), Integrating Traditional Healing into Counseling and Psychotherapy (pp. 293-304). Thousand Oaks, California: Sage Publications.

Mussell, B., Cardiff, K., \& White, J. (2004). The Mental Health and Well-Being of Aboriginal Children and Youth: Guidance for New Approaches and Services (Vol. 1, Rep. 9). Vancouver, British Columbia: University of British Columbia, Children's Mental Health Policy Research Program.

Pape, B. \& Galipealt, J-P. (2002, April). Mental Health Promotion for People with Mental Illness: A Discussion Paper. Ottawa, Ontario: Health Canada, Mental Health Promotion Unit.

Pollett, H. (2007, June 18). Mental Health Promotion: A Literature Review. Ottawa, Ontario: Canadian Mental Health Association. Retrieved February 29, 2009, from http://
www.cmhanl.ca/pdf/Mental $\% 20$ Health $\% 20$ Promotion $\% 20$ Lit.\%20Review\%20June\%2018.pdf.

Royal Commission on Aboriginal Peoples. (2006, February 8). Appendix E: ethical guidelines for research. In Report of the Royal Commission on Aboriginal Peoples. (Vol. 5). Retrieved March 16, 2009, from http://www.ainc-inac.gc.ca/ch/ rcap/sg/sgmm_e.html.

Shepard, B., O’Neill, L., \& Guenette, F. (2006). Counselling with First Nations women: considerations of oppression and renewal. International Journal for the Advancement of Counselling, 28(3), 227-240.

Smith, L.T. (1999). Decolonizing Methodologies: Research and Indigenous Peoples. London, United Kingdom: Zed Books Ltd.

Smye, V. \& Mussell, B. (2001, July). Aboriginal Mental Health: What Works Best. Vancouver, British Columbia: University of British Columbia, Mental Health Evaluation \& Community Consultation Unit. Retrieved February 29, 2009, from http://www.mheccu.ubc.ca/documents/publications/discussion-paper.pdf.

The Health Communications Unit. (2007). Evaluating Health Promotion Programs. Toronto, Ontario: University of Toronto, The Centre for Health Promotion. Retrieved February 10, 2009, from http://www.thcu.ca/infoandresources/publications/EVALMaster.Workbook.v3.6.08.15.07.pdf.

Walker, R. (2009, May). Social Housing and the Role of Aboriginal Organizations in Canadian Cities (Vol. 14, No. 4). Montreal, Quebec: Institute for Research on Public Policy.

Wilson, A. (2004). Living Well: Aboriginal Women, Cultural Identity and Wellness. Winnipeg, Manitoba: The Prairie Women's Health Centre of Excellence. Retrieved March 24, 2009, from http://www.uwinnipeg.ca/admin/vh_external/ pwhce/pdf/livingWell.pdf.

World Health Organization. (1986). Ottawa Charter for Health Promotion. Ottawa, Ontario: First International Conference on Health Promotion. Retrieved April 8, 2009, from http:// www.who.int/hpr/NPH/docs/ottawa charter_hp.pdf.

World Health Organization. (2007, September). Mental health: strengthening mental health promotion. Retrieved February 29, 2009, from http://www.who.int/mediacentre/factsheets/ fs220/en/. 